\title{
APLIKASI MOBILE COMMERCE (M-COMMERCE) BERBASIS ANDROID HYBRID
}

\author{
Sandro Alfeno ${ }^{1}$, Wury Intan Tiana ${ }^{2}$ \\ ${ }^{1}$ Dosen STMIK Raharja Jurusan Teknik Informatika, ${ }^{2}$ Mahasiswa STMIK Raharja \\ Jurusan Teknik Informatika \\ 1,2Jl.Jendral Sudirman No.40, Modern Cikokol, Tangerang \\ e-mail: ${ }^{1}$ sandro@raharja.info, ${ }^{2}$ wury@raharja.info
}

\begin{abstract}
ABSTRAK
Banyaknya penggunaan sistem operasi Android membuat para developer bersaing dalam membuat aplikasi berbasis Android. Salah satunya dalam bisnis, pembuatan sistem penjualan yang dapat berjalan dalam smartphone berbasis Android sangat digemari oleh sebagian besar masyarakat karena dapat memudahkan dalam melakukan transaksi jualbeli. Berdasarkan hasil penelitian sistem penjualan pada PT Gemanusa Sentra Teknologi masih memiliki beberapa kekurangan. Untuk menyelesaikan masalah tersebut, maka dibuatlah aplikasi Mobile Commerce (M-Commerce) dengan menggunakan REST API sebagai metode komunikasi antara Client dan Server. Dengan adanya aplikasi ini akan memudahkan penggunanya untuk melakukan transaksi jual beli karena dapat digunakan dimana saja dan kapan saja.
\end{abstract}

Kata Kunci: Aplikasi Mobile, E-Commerce, M-Commerce.

\begin{abstract}
The number of uses of the Android operating system makes developers compete in making Android-based applications. One of them is in business, making a sales system that can run on Android-based smartphones is very popular with most people because it can facilitate buying and selling transactions. Based on the results of the research, the sales system at PT Gemanusa Sentra Teknologi still has some shortcomings. To solve this problem, a Mobile Commerce (M-Commerce) application is created by using the REST API as a communication method between Client and Server. With this application, it will be easier for users to make buying and selling transactions because they can be used anywhere and anytime.
\end{abstract}

Keywords: Mobile Application, E-Commerce, M-Commerce. 


\section{PENDAHULUAN}

Seiring dengan perkembangan teknologi, kebutuhan masyarakat akan smartphone dengan fitur yang canggih semakin meningkat. Smartphone kini telah menjadi gaya hidup sebagian besar masyarakat. Perlahan smartphone menggantikan fungsi komputer (desktop) untuk melakukan kegiatan sehari-hari termasuk kegiatan bisnis. Hal ini terlihat dari persentase penjualan sistem operasi di seluruh dunia, berdasarkan StatCounter GlobalStats periode juni 2017 sampai juni 2018, sistem operasi Android memimpin dengan persentase $39.96 \%$ sedangkan Windows berada di peringkat kedua dengan $36.48 \%$ dan IOS dengan $13.06 \%$ pada peringkat ketiga. ${ }^{[1]}$. Sebelumnya, untuk dapat membuat aplikasi mobile, dibutuhkan bahasa pemrograman khusus untuk suatu platform mobile seperti, Java untuk Android dan Swift untuk IOS. Hal ini menyulitkan programmer karena harus menguasai banyak bahasa pemrograman. Kini sudah banyak framework yang dihasilkan untuk membantu programmer dalam membuat aplikasi mobile. Dengan framework ini, programmer hanya perlu menguasai bahasa pemrograman web seperti HTML, CSS dan Javascript untuk membuat aplikasi mobile yang dapat berjalan di platform mobile apapun. Dalam kegiatan bisnis, aplikasi yang dibutuhkan marketing adalah aplikasi yang dapat memudahkan dalam kegiatan pemasaran. Untuk dapat meningkatkan kualitas dalam melayani pelanggan, marketing membutuhkan aplikasi yang dapat menampilkan produknya dengan cepat dan mudah serta aplikasi yang dapat memudahkan dalam pembuatan laporan penjualan. Aplikasi $e-$ commerce yang dapat diinstall di smartphone, agar dapat digunakan di mana pun dan kapan pun.

PT Gemanusa Sentra Teknologi merupakan perusahaan yang bergerak di bidang Teknologi Informasi, sebagai IT Consultant, Software Developer dan System Integrator. Perusahan ini juga menjual berbagai alat elektronik seperti IC, Crystal, Socket dan lainnya yang diproduksi sendiri. Akan tetapi, penjualan yang dilakukan masih menggunakan cara manual dan menggunakan website yang tidak diupdate. Website ini hanya menampilkan beberapa produk dengan detail yang tidak lengkap dan hanya developer yang memiliki akses untuk mengedit website ini. Hal ini membuat marketing kesulitan untuk memasarkan produknya. Tujuan dari penelitian ini adalah untuk membuat Aplikasi Mobile-Commerce berbasis Android Hybrid dengan menggunakan bahasa pemrograman web dan dapat diaplikasikan dalam platform mobile. Untuk dapat memudahkan bagian marketing dalam mengiklankan produknya serta memudahkan dalam pembuatan laporan penjualan. Memudahkan pelanggan dalam mengetahui produk-produk apa saja yang dijual serta dalam melakukan transaksi jual-beli.

Metode pengembangan sistem yang digunakan dalam pembuatan aplikasi MCommerce ini adalah metode SDLC (System Development Life Cycle) dengan model Waterfall:

a. Tahap Analisa Kebutuhan

Metode ini diwali engan tahapan pengumpulan dan penyusunan kebutuhan sistem secara lengkap dari sistem yang akan dibangun.

b. Tahap Perancangan

Pada tahap ini, kebutuhan yang telah disusun sebelumnya diubah menjadi bentuk "blueprint" sebuah perangkat lunak. Rancangan ini meliputi aliran kerja manajemen serta desain sistem yang diperlukan.

c. Tahap Implementasi 
Setelah rancangan telah dibuat maka pada tahap ini rancangan tersebut akan diimplementasikan. Desain pada sistem akan diterjemahkan ke dalam kode-kode bahasa pemrograman yang telah ditentukan.

d. Tahap Pengujian

Sistem yang telah diimplementasikan kemudian disatukan dan diuji secara keseluruhan. Tujuan tahap ini adalah untuk mengevaluasi apakah sistem yang dibuat telah memenuhi persyaratan.

e. Tahap Pemeliharaan

Tahap ini merupakan tahapan terakhir dari metode ini. Pemeliharaan bertujuan untuk memastikan bahwa sistem yang telah dibuat dapat digunakan dengan stabil dan terbebas dari error atau bug.

\section{METODE PENELITIAN}

\section{E-Commerce}

E-commerce adalah suatu cara dalam berbelanja atau berdagang secara online yang memanfaatkan fasilitas jaringan internet dimana terdapat website yang dapat menyediakan layanan seperti "get and deliver". [2]

E-commerce didefinisikan sebagai mekanisme dari transaksi jual dan beli dengan menggunakan fasilitas jaringan internet sebagai media komunikasi agar dapat melakukan transaksi perdagangan. ${ }^{[3]}$

Dapat disimpulkan bahwa, E-commerce merupakan segala kegiatan yang berhubungan dengan transaksi perdagangan seperti menjual dan membeli suatu produk yang dilakukan secara online atau melalui jaringan internet untuk meraih keuntungan.

Sedangkan $M$-Commerce adalah sebuah sistem e-commerce yang dapat diakses melalui perangkat mobile (smartphone) agar dapat digunakan dimana saja dan kapan saja.

2. Aplikasi Mobile

Aplikasi Mobile adalah jenis perangkat lunak aplikasi yang dirancang untuk dapat berjalan pada perangkat seluler, seperti smartphone dan juga tablet. Aplikasi mobile ini terbagi menjadi 3 jenis, yaitu:

a. Aplikasi Native yaitu aplikasi yang dibuat secara khusus untuk platform tertentu dengan menggunakan teknologi pengembangan dan juga API (Aplication Protocol Interface) khusus untuk platform tersebut.

b. Aplikasi Web adalah aplikasi yang dibuat dengan pengembang web seperti HTML, CSS dan Javascript seperti sebuah website tetapi dikembangkan agar dapat diakses melalui browser pada smartphone.

c. Aplikasi Hybrid merupakan aplikasi gabungan dari aplikasi native dan web. Dibuat dengan menggunakan bahasa pemrograman web (HTML, CSS, dan JavaScript) yang didesain sedemikian rupa agar dapat dijalankan di berbagai platform perangkat seluler. Aplikasi ini dapat mengakses perangkat hardware yang tersedia seperti kamera, GPS dan yang lainnya.

Pendekatan pengembang hybrid dengan melibatkan teknologi web yang dapat dijalankan pada aplikasi native, memberikan keuntungan untuk mengoptimalkan kelebihan dari kedua teknologi tersebut. ${ }^{[4]}$

3. Android

Android merupakan sistem operasi berbasis Linux yang dikembangkan oleh Android, Inc kemudian dibeli oleh Google yang secara resmi di rilis pada tahun 
2007. Tidak seperti sistem operasi mobile lain, android mengizinkan siapa pun untuk memodifikasi, menyesuaikan dan mendistribusikan kode dari sistem operasi ini dan tidak perlu membayar untuk lisensi apapun.

Saat ini Google telah merilis 24 versi dari sistem operasi Android sejak tahun 2008 dan terus melakukan investasi besar untuk mengembangkan dan memperbaiki sistem operasi ini.

4. Ionic Framework

Menurut Khanna et al. (2017:14), "Ionic framework is a Hybrid App development framework that enables developers to build Native-looking Mobile Apps using web technologies (HTML5, CSS3, and JS). Ionic Framework is completely open source so that developers can build and publish their app to the marketplace without any cost." [5]

Ionic adalah SDK front-end untuk membangun aplikasi seluler lintas platform. Dibangun di atas Angular, Ionic juga menyediakan platform untuk mengintegrasikan layanan seperti notifikasi push dan analitik. Saat ini, Ionic merupakan platform pengembangan teknologi mobile lintas platform yang paling popular di dunia. Ionic merupakan framework open source yang berlisensi MIT yang menawarkan komponen web dan aplikasi native terbaik untuk membangun aplikasi hybrid yang sangat interaktif.

5. AngularJs

AngularJS bukan merupakan library Javacript melainkan sebuah framework Javascript yang mengadopsi konsep MVC (Model, View, Controller) untuk membangun aplikasi web. ${ }^{[6]}$

AngularJS merupakan versi pertama framework open source aplikasi web berbasis javascript yang dirilis pada tahun 2009 dan dikembangkan oleh Misko Hevery dan Adam Abrons sebelum dimaintain oleh Google.

6. Laravel

Laravel merupakan framework PHP open source yang dikembangkan oleh Taylor Otwell yang berada di bawah lisensi MIT yang bertujuan untuk mempermudah para developer untuk membuat sebuah web dengan sintaks yang sederhana, elegan, ekspresif dan juga menyenangkan. Dengan Laravel, dapat mengurangi tugas-tugas umum yang dikerjakan oleh seorang developer, seperti routing, session dan caching. [7]

7. Apache Cordova

Menurut Khanna et al. (217:143), "Apache Cordova is a technology that lets any web application be packaged as a native mobile application while also providing access to device features". [5]

Cordova membungkus aplikasi HTML / JavaScript ke dalam penampung asli yang dapat mengakses fungsi perangkat dari beberapa platform. Fungsi-fungsi ini diekspos melalui API JavaScript terpadu, memungkinkan Anda dengan mudah menulis satu set kode untuk menargetkan hampir semua ponsel atau tablet di pasar saat ini dan mempublikasikan ke toko aplikasinya.

8. REST API

REST (Representional State Transfer) adalah arsitektur dari suatu metode komunikasi yang secara umum menggunakan protokol HTTP untuk membuat dan mengatur komunikasi data agar sistem dapat memiliki performa yang baik dan mudah untuk dikembangkan. ${ }^{[8]}$ 
Nama REST sendiri diciptakan oleh Roy Fielding dari Universitas California. Rest ini adalah layanan web yang sangat disederhanakan dan lebih ringan dibandingkan dengan SOAP. Prinsip utama dibalik desain REST adalah kinerja, skalabilitas, kesederhanaan probabilitas dan dan dapat dimodifikasi.

REST adalah tentang memisahkan client dan server. Ini berarti bahwa client dan server memiliki tugas dan tanggung jawab yang berbeda dan terpisah, sehingga tidak bertanggung jawab dengan tugas lainnya. Misalnya, client tidak bertanggung jawab atas penyimpanan data di server karena itu merupakan tugas dari sisi server. Setiap permintaan (request) yang datang dari client akan memiliki semua informasi yang diperlukan untuk melayani permintaan. Response yang akan diterima client pun akan didasarkan pada permintaan tanpa melihat keadaan apa pun selain yang diminta. [9]

\section{Studi Pustaka (Literature Review)}

Studi pustaka diperlukan dalam upaya untuk melengkapi dan mengembangkan penelitian ini. Adapun studi pustaka yang terkait dengan judul penelitian ini adalah sebagai berikut:

1. Penelitian yang dilakukan oleh M. Rofiq dan Suci Imani Putri yang berjudul "Perancangan Sistem Pemesanan Rumah Sakit di Kota Malang Menggunakan Ionic Framework berbasis Mobile Phone" pada tahun 2017. Penelitian ini menggunakan Ionic Framework untuk membangun aplikasi tersebut dari sisi client serta penggunaan PHP dan MySQ1 untuk memabngun aplikasi dari sisi server. ${ }^{[10]}$

2. Penelitian yang dilakukan oleh Arminditya Fajri Akbar dan Prihatin Oktivasari yang berjudul "Aplikasi Monitoring Kebutuhan Konsumsi Air Putih Harian Berbasis Android Menggunakan Ionic Dan Laravel Pada Rancang Bangun Smart Bottle" pada tahun 2017. Penelitian ini membahas tentang aplikasi yang dirancang dengan konsep hybrid menggunakan teknologi web seperti HTML, CSS dan Javascript. Kemudian penggunaan Laravel untuk membangun REST API agar aplikasi terhubung dengan database. ${ }^{[11]}$

3. Penelitian yang dilakukan oleh Achmad Sidik, Sutarman dan Marlenih yang berjudul "Perancangan Sistem Informasi Penjualan Perumahan Citra Raya" pada tahun 2017. Penelitian ini dilakukan untuk merancang dan membangun sistem penjualan yang dapat mempermudah penggunanya dalam mempromosikan dan menjual produknya. Sistem penjualan dirancang dengan menggunakan alat bantu UML, seperti Use Case Diagram dan Class Diagram untuk menggambarkan sistem yang diusulkan. ${ }^{[12]}$

4. Penelitian yang dilakukan oleh Andi Triansah, Dedi Cahyadi dan Indah Fitri Astuti yang berjudul "Membangun Aplikasi Web Dan Mobile Android Untuk Media Pencarian Kost Menggunakan Phonegap Dan Google Maps Api" pada tahun 2015. Aplikasi ini dibuat dengan menggunakan teknologi berbasis web (HTML, CSS dan Javascript) untuk membuat aplikasi mobile asli (native) dan dengan menggunakan Phonegap agar aplikasi dapat berjalan di berbagai platform mobile. ${ }^{[13]}$

5. Penelitian yang dilakukan oleh Achmad Sidik, Arnie R. Mariana dan Chandra Mahardika yang berjudul "Sistem Informasi Pengenalan Produk Safety Shoes Berbasis Android" pada tahun 2016. Penelitian ini dibuat untuk memenuhi kebutuhan perusahaan akan aplikasi yang dapat memberikan informasi dengan 
mudah dan cepat kepada pelanggannya melalui aplikasi Android. Aplikasi yang dibangun dengan menggunakan HTML5, Javascript dan CSS dan dengan bantuan framework open-source Apache Cordova. ${ }^{[14]}$

\section{HASIL DAN PEMBAHASAN}

1. Arsitektur Sistem

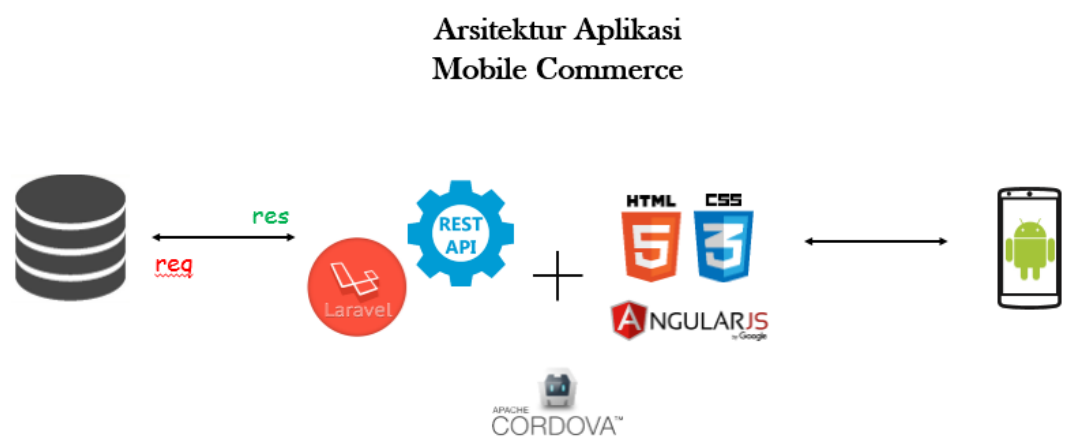

Gambar 1 Arsitektur Sistem

Aplikasi ini dibuat dengan menggunakan bahasa pemrograman untuk web seperti HTML5, CSS dan AngularJs untuk front end dan penggunaan framework Laravel untuk back end serta bantuan REST API untuk berkomunikasi (mengirim dan menerima data) dengan database. Sedangkan Apache Cordova digunakan untuk memaketkan pemrograman tersebut agar dapat dijalankan melalui perangkat Android.

2. Perancangan

Perancangan aplikasi ini dibuat dengan menggunakan alat bantu UML (Unified Modelling Languange) untuk membuat diagram yang menggambarkan aplikasi ini. Diagram yang digunakan adalah sebagai berikut.

a. Use Case Diagram Aplikasi M-Commerce

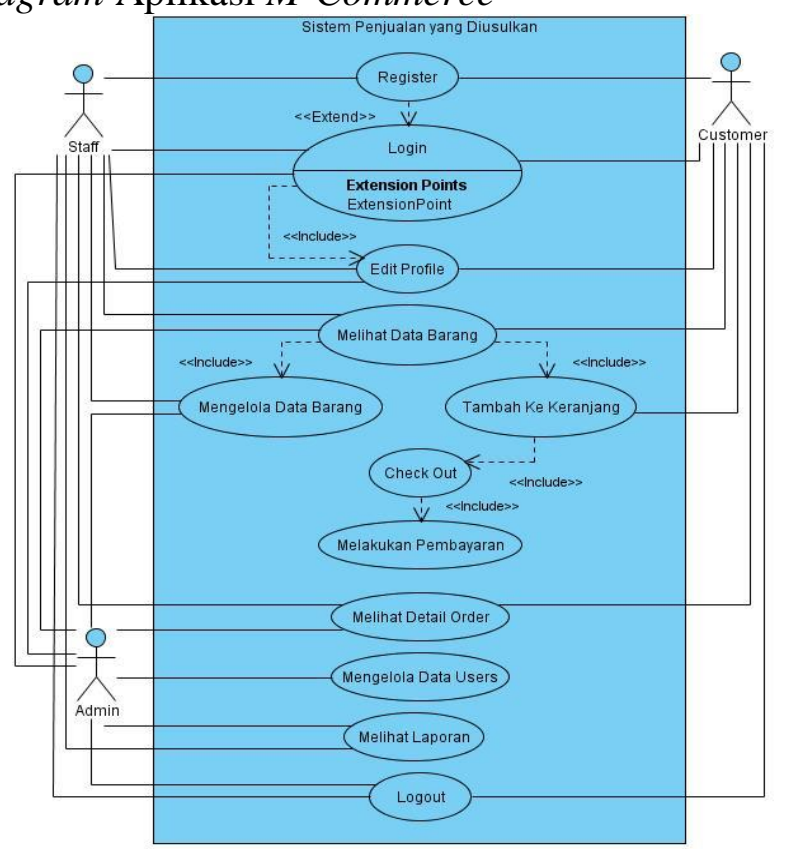

Gambar 2 Use Case Diagram Aplikasi M-Commerce 
Berdasarkan diagram diatas terdapat:

a. Satu (1) buah sistem yang meliputi seluruh kegiatan dalam sistem penjualan.

b. Tiga (3) aktor yang melakukan kegiatan, yakni: Staff, Admin dan Customer.

c. Dua Belas (12) buah use case yang dilakukan oleh aktor-aktor tersebut.

b. Class Diagram Aplikasi M-Commerce
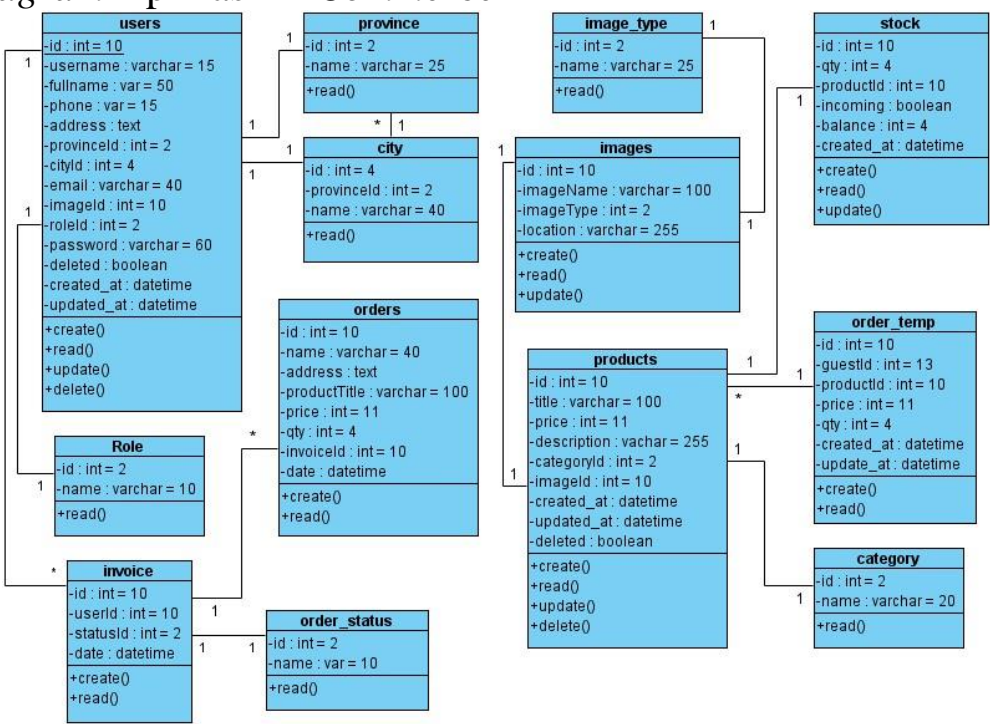

Gambar 3 Class Diagram Aplikasi M-Commerce

Berdasarkan diagram diatas terdapat tiga belas tabel, yaitu tabel users, tabel province, tabel city, tabel role, tabel images, tabel image_type, tabel products, tabel category, tabel stock, tabel order_temp, tabel orders, tabel invoice, dan tabel order_status.

\section{Implementasi}

Pada tahap implementasi dan pembahasan aplikasi M-Commerce ini penulis menggunakan emulator dari AVDs (Android Virtual Devices) Manager dengan menggunakan device Nexus 5X dan API Level 21 Android 5.0.1 (Lollipop).

a. Tampilan Home

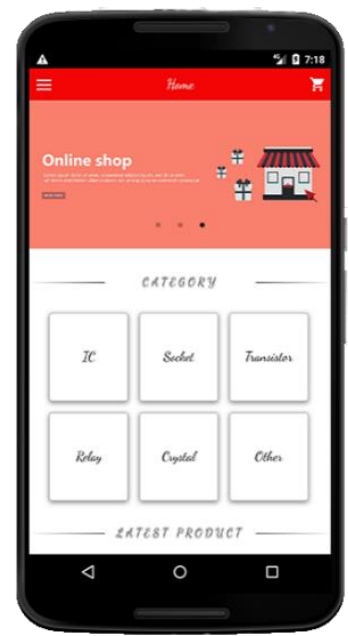

b. Tampilan Login

Gambar 4 Tampilan Home 
c. Tampilan Dashboard

Gambar 5 Tampilan Login

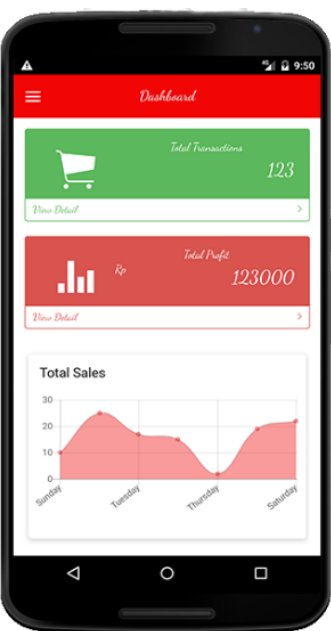

d. Tampilan Products

Gambar 6 Tampilan Dashboard

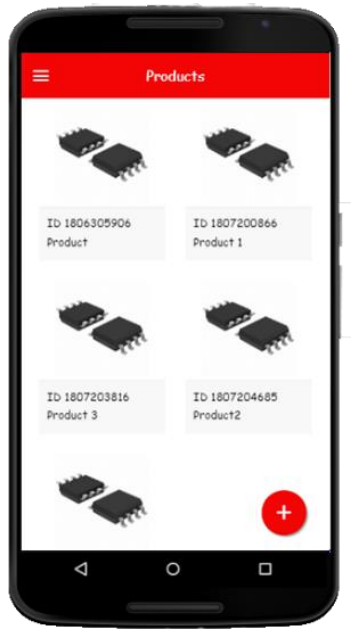

Gambar 7 Tampilan Products 
e. Tampilan New Products

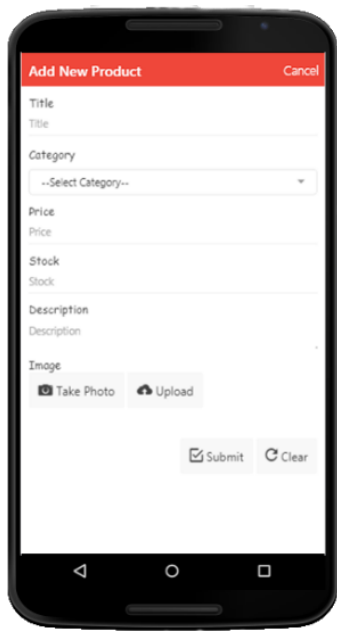

f. Tampilan Order

Gambar 8 Tampilan New Products

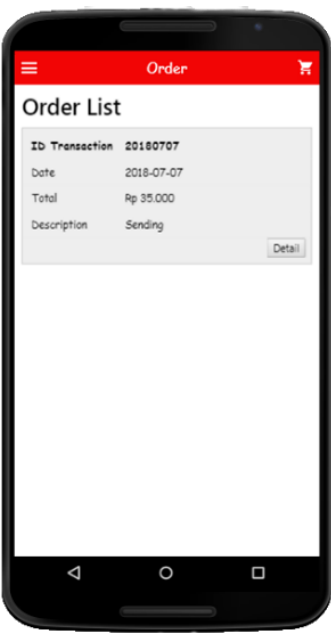

Gambar 9 Tampilan Order

g. Tampilan Users

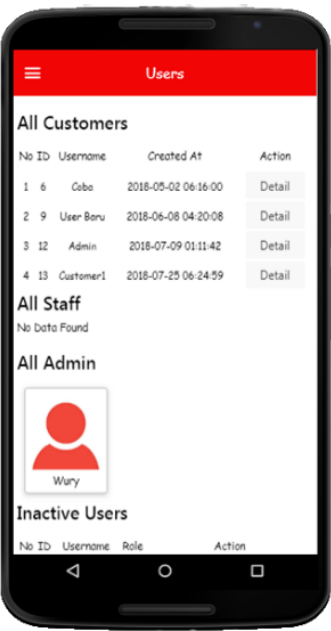

Gambar 10 Tampilan Users 


\section{KESIMPULAN}

Berdasarkan hasil penelitian yang telah dilakukan di PT Gemanusa Sentra Teknologi, maka dapat diambil kesimpulan sebagai berikut:

a. Untuk dapat membuat aplikasi penjualan yang dapat diinstall di media smartphone, diperlukan sebuah framework aplikasi mobile hybrid dan encapsulator Apache Cordova untuk memaketkan aplikasi tersebut agar dapat diinstal pada platform Android.

b. Untuk dapat terintegrasi dengan database diperlukan sebuah web service seperti REST API agar dapat menerima dan mengirim data dengan mudah.

\section{SARAN}

Untuk meningkatkan kinerja dari Aplikasi ini, terdapat beberapa saran agar menjadi masukan untuk penelitian berikutnya, seperti:

a. Penggunaan berbagai payment gateway agar pembeli dapat menentukan cara pembayaran yang paling mudah dan paling nyaman.

b. Menambahkan fitur agar pembeli dapat dengan mudah melakukan pembelian produk yang berupa perangkat lunak.

\section{DAFTAR PUSTAKA}

[1] Statcounter GlobalStats. 2018. Diambil dari http://gs.statcounter.com/osmarket-share\#monthly-201706-201806-bar (24 Juli 2018).

[2] Program Studi Akuntansi FEB Univ. Ma Chung. 2018. Studi Kasus Sistem Informasi Manajemen: Volume 2. Jawa Timur: Seribu Bintang.

[3] Sakti, Nufransa Wira. 2014. Buku Pintar Pajak E-Commerce. Jakarta: Transmedia Pustaka.

[4] Tolle, Herman, Aryo Pinandito, Agi Putra Kharisma dan Ratih Kartika Dewi. Pengembangan aplikasi Perangkat Bergerak (Konsep \& Implementasi). 2017. Malang: Universitas Brawijaya Press.

[5] Khanna, Rahat, Sani Yusuf dan Hoc Phan. 2017. Ionic: Hybrid Mobile App Development. Birmingham: Packt Publishing Ltd.

[6] Enterprise, Jubilee. 2017. Otodidak Pemrograman Javascript. Jakarta: PT Elex Media Komputindo.

[7] Enterprise, Jubilee. 2016. Mengenal PHP Menggunakan Framework Laravel. Jakarta: PT Elex Media Komputindo.

[8] Yellavula, Naren. 2017. Building RESTful Web Services with Go. Birmingham: Packt

[9] Ahmad, Haafiz Waheed-ud-din. 2017. Building RESTful Web Services with PHP 7. Birmingham: Packt.

[10] Rofiq, M. dan Suci Imani Putri. 2017. Perancangan Sistem Pemesanan Rumah Sakit di Kota Malang Menggunakan Ionic Framework berbasis Mobile Phone. Jurnal Ilmiah Teknologi Informasi Asia. Vol. 11, No.2:171-178.

[11] Akbar, Arminditya Fajri dan Prihatin Oktivasari. 2017. Aplikasi Monitoring Kebutuhan Konsumsi Air Putih Harian Berbasis Android Menggunakan Ionic Dan Laravel Pada Rancang Bangun Smart Bottle. Jurnal POLITEKNOLOGI. Vol. 16, No.2, Mei 2017:149-156.

[12] Sidik, Achmad, Sutarman dan Marlenih. 2017. Perancangan Sistem Informasi Penjualan Perumahan Citra Raya. Jurnal Sisfotek Global. Vol. 7, No.1, Maret 2017: 56-65. 
[13] Triansah, Andi, Dedi Cahyadi dan Indah Fitri Astuti. 2015. Membangun Aplikasi Web Dan Mobile Android Untuk Media Pencarian Kost Menggunakan Phonegap Dan Google Maps Api. Jurnal Informatika Mulawarman. Vol. 10, No.1, Februari 2015: 58-62.

[14] Sidik, Achmad, Arnie R. Mariana dan Chandra Mahardika. 2017. Sistem Informasi Pengenalan Produk Safety Shoes Berbasis Android. Jurnal Sisfotek Global. Vol. 6, No.2, September 2016: 40-46. 